nephron

Practice
Nephron 2016;132:1-4

DOI: $10.1159 / 000443340$
Received: November 25, 2015

Accepted after revision: December 12, 2015

Published online: January 9, 2016

\title{
The Complement System in Hemodialysis Patients: Getting to the Heart of the Matter
}

\author{
Martin H. de Borst \\ Department of Internal Medicine, Division of Nephrology, University of Groningen, University Medical Center Groningen, \\ Groningen, The Netherlands
}

Cardiovascular disease is by far the leading cause of death in patients with end-stage renal disease (ESRD), comprising more than half of all known causes of death [1]. Arteriosclerosis, characterized by medial calcification and sclerosis, and atherosclerosis, characterized by lipid plaque formation, are 2 distinct processes that play a major role in the etiology of cardiovascular disease in ESRD. It is incompletely understood which factors drive the accelerated arteriosclerosis and atherosclerosis observed in advanced chronic kidney disease.

Arteriosclerosis is characterized by progressive calcification of the arterial tunica media. Vascular calcification is already abundantly present in adolescent patients with ESRD [2], and it is therefore not surprising that cardiovascular disease is the main cause of death even in children and young adults with ESRD [3]. The development and progression of vascular calcifications, and subsequent dismal clinical outcomes [4], is accompanied by profound deregulations in calcium/phosphate metabolism in many ESRD patients. Consequently, the involvement of serum phosphate and its regulating hormone fibroblast growth factor 23 (FGF23) as potential risk factors for adverse cardiovascular outcomes in ESRD has been extensively studied over the past decade $[5,6]$. These studies have consistently demonstrated associations be-

\begin{tabular}{ll}
\hline KARGER & ( 2016 The Author(s) \\
& Published by S. Karger AG, Basel \\
& $1660-8151 / 16 / 1321-0001 \$ 39.50 / 0$ \\
E-Mail karger@karger.com & Ther \\
www.karger.com/nef & Thisticle is licensed under the Creative Commons Attribution- \\
& NonCommercial-NoDerivatives 4.0 International License (CC BY- \\
& NC-ND) (http://www.karger.com/Services/OpenAccessLicense). \\
Usage and distribution for commercial purposes as well as any dis- \\
tribution of modified material requires written permission.
\end{tabular}

tween high levels of serum phosphate and FGF23 and cardiovascular morbidity and mortality. Yet, so far, no intervention has been shown to simultaneously restore calcium/phosphate metabolism and improve cardiovascular prognosis. Furthermore, although it is plausible to assume that deregulated calcium/phosphate metabolism contributes to media calcification, its potential role in atherosclerotic plaque formation is less clearly defined. In atherosclerosis additional processes, including the activation of pro-inflammatory pathways, may instead play a more prominent role.

The complement system is an important component of innate immunity that primarily functions as a host defense against pathogenic infections. Uncontrolled activation of the complement system can result in renal and systemic diseases including atypical hemolytic uremic syndrome (aHUS) [7] and membranoproliferative glomerulonephritis [8]. Furthermore, deregulations in the complement system have also been linked with endothelial dysfunction, atherosclerosis, and impaired coagulation [9]. Of interest, several studies in non-renal patients have shown associations between complement components and cardiovascular disease. Particularly a higher circulating level of $\mathrm{C} 3$, which plays a central role in the activation of the complement pathway (fig. 1), has been 


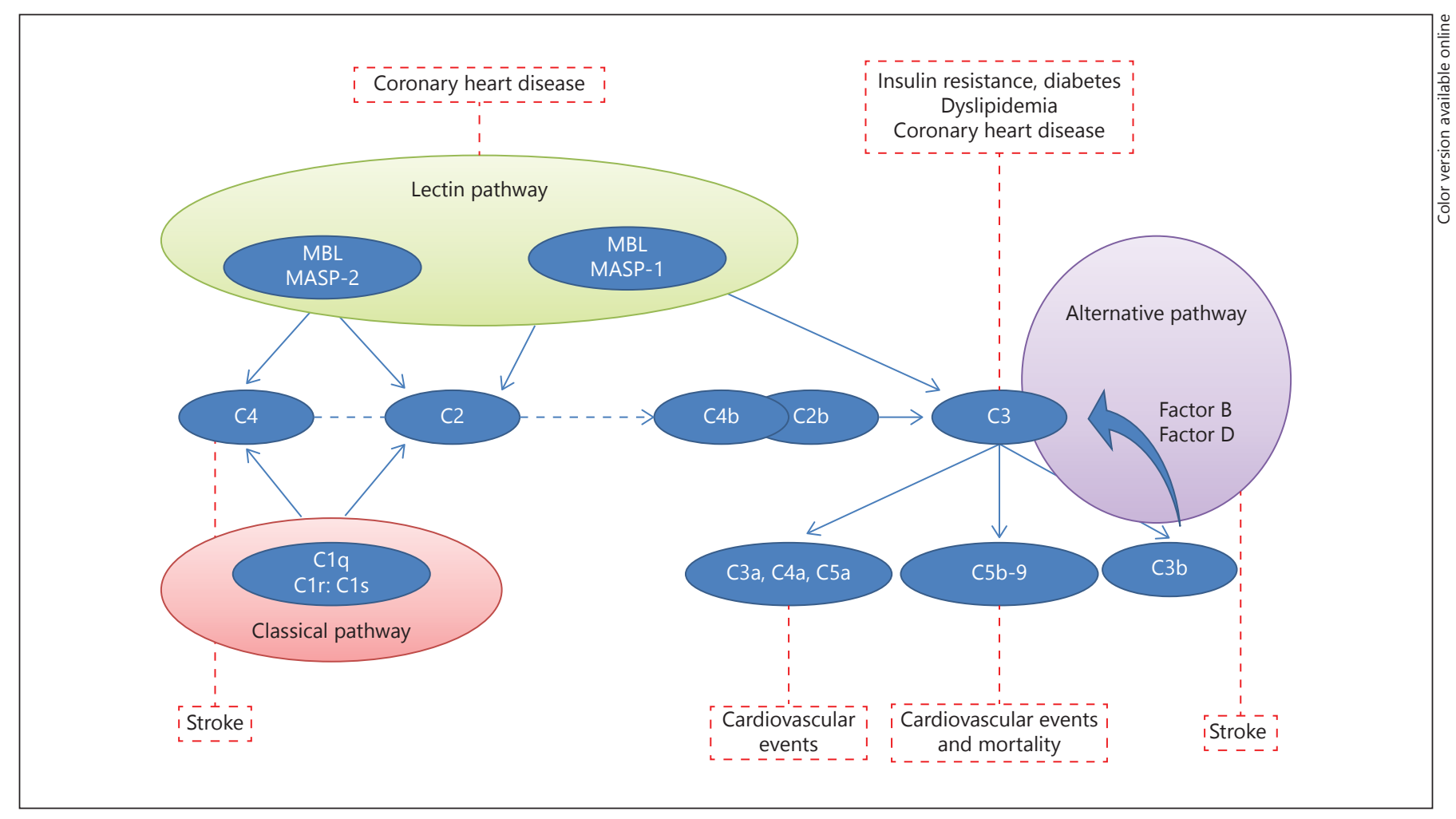

Fig. 1. The complement system and cardiovascular risk. Overview of the main components of the complement system, and its associations with cardiovascular disease and its risk factors. The complement system consists of the classical pathway, the lectin pathway, and the alternative pathway, all of which converge on the C3-mediated generation of C5b-9, the MAC, C3a-5a, and C3b.
Associations with cardiovascular disease and/or risk factors are indicated in dotted lines, and smaller font sizes reflect weak evidence (limited studies and/or sample size). MASP = Mannosebinding-lectin-associated serine proteases; $\mathrm{MBL}=$ mannose-binding lectin. linked with insulin resistance and incident diabetes [10, 11], disturbed lipid metabolism [12], and incident and prevalent coronary heart disease $[13,14]$. Besides C3, higher circulating levels of mannose-binding lectin have also been associated with incident coronary artery disease [15], whereas factor D (also known as adipsin) and C4 have been linked with the development of stroke [16, 17]. More downstream, the role of C5b-9, comprising the membrane attack complex (MAC), has been implicated in atherosclerotic plaque formation in preclinical studies [18], and its soluble form has been associated with allcause mortality and major cardiovascular events in patients with myocardial infarction [19]. Similarly, the downstream component $\mathrm{C} 5 \mathrm{a}$ has been associated with cardiovascular disease in patients with advanced atherosclerosis [20]. Although these data come from a limited number of studies performed in generally small cohorts, and reported data have not always been consistent [9], these findings do warrant further investigation of the role of the complement system in patients with advanced chronic kidney disease.

In this issue of Nephron, Lines et al. [21] link activation of the complement system with an increased risk of cardiovascular events in hemodialysis patients. The authors performed a post-hoc analysis of a clinical trial in which 260 hemodialysis patients were randomized to dialysis with a vitamin E-coated dialysis membrane or a non-vitamin E-coated equivalent. The type of dialysis membrane did not modify mortality at one year after initiation of the trial, nor did this affect circulating levels of the complement components $\mathrm{C} 3$, factor $\mathrm{D}$, factor $\mathrm{H}$, or soluble C5b-9. However, when assessing complement components measured at baseline, the authors found that a higher baseline $\mathrm{C} 3$ level was associated with a higher risk of subsequent cardiovascular events. Given the relatively small sample size and limited number of patients developing a cardiovascular event $(n=33)$, the authors could not adjust for potential confounders. Thus, this pioneer- 
ing study should be followed up by larger and more extensively adjusted analyses in order to substantiate this observation. Interestingly, when additionally studying the relationship between C5b-9 and cardiovascular events, the authors found that both a high and a low level of C5b-9 was associated with a higher cardiovascular risk in hemodialysis patients. Further studies are needed to understand the implications of this observation, which can at least partly be reconciled with previous data [19].

Which mechanisms could connect complement activation and the increased risk of cardiovascular disease in hemodialysis patients? First, complement activation may induce a pro-inflammatory state in the vascular wall, promoting atherosclerotic plaque formation and destabilization. Second, cardiovascular fat serves as a source of C3, and hence $\mathrm{C} 3$ could be merely a marker of prevalent atherosclerosis [22]. This further supports the need for analyses adjusted for markers and/or risk factors of prevalent atherosclerosis such as obesity, diabetes and hypertension. A third possibility, also raised by Lines et al. [21], is that complement activation could well be induced by dialysis treatment in itself, for instance, due to the use of bioincompatible materials including the dialysis membrane [23]. It is well established that hemodialysis in itself inflicts cardiovascular stress, which could be mediated by hemodynamic effects [24], but also by a pro-inflammatory profile of patients prone to experience hemodialysisinduced cardiac stress [25]. This pro-inflammatory state may, in turn, be related to dialysis (membrane)-induced complement activation in this category of patients. Unfortunately, the vitamin E-coated membranes used in the active treatment arm of the trial reported by Lines et al. [21] affected neither complement activation (although the effect on more specific markers such as $\mathrm{C} 3 \mathrm{~d}$ could not be assessed in this study) nor clinical outcomes [21]. On the other hand, the authors also observed declining $\mathrm{C} 3$ levels over time in both study arms (p-trend $<0.0001$ ), which would render a main role for hemodialysis treatment as a cause of complement activation less likely.
Should the complement system be considered a novel therapeutic target to improve cardiovascular outcomes in hemodialysis patients? The therapeutic potential of interventions targeting the complement system to modify cardiovascular risk in diabetic patients was recently highlighted by the identification of a novel peptide that abolished C3-induced prolongation of fibrin clot lysis, by interfering with the interaction between $\mathrm{C} 3$ and fibrinogen [26]. This peptide could provide a novel therapy targeting thrombosis in patients with diabetes. The complement C5 inhibitor eculizumab has shown beneficial effects not only in patients with aHUS, but also in some (but not all) patients with dense-deposit disease [27]. Importantly, a recent study also showed reduction of inflammation, endothelial damage and thrombosis by eculizumab in patients with aHUS [28], but whether such effects could also be observed in ESRD patients without hemolytic uremic syndrome is unclear. Given the high costs of eculizumab, its potential application to reduce the excessive cardiovascular risk in the hemodialysis population seems currently one bridge too far. Meanwhile, it may be worthwhile to further document the relationship between complement components and cardiovascular outcomes in well-adjusted analyses in larger cohorts, and to study the cardiovascular protective effects of interventions targeting complement activation, including eculizumab, in selected patient groups.

\section{Disclosure Statement}

The author has no conflicts of interest to declare.

\section{Acknowledgments}

Dr. M.H. de Borst is supported by grants from the Dutch Kidney Foundation (NIGRAM consortium, CP10.11) and the Netherlands Organization for Scientific Research (Veni grant 016.146.014).

\section{References}

1 United States Renal Data System: 2015 USRDS Annual Data Report: Epidemiology of Kidney Disease in the United States. Bethesda, National Institutes of Health, National Institute of Diabetes and Digestive and Kidney Diseases, 2015.

2 Goodman WG, Goldin J, Kuizon BD, Yoon C, Gales B, Sider D, Wang Y, Chung J, Emerick A, Greaser L, Elashoff RM, Salusky IB: Coro-

The Complement System in Hemodialysis Patients nary-artery calcification in young adults with end-stage renal disease who are undergoing dialysis. N Engl J Med 2000;342:1478-1483.

3 Mitsnefes MM: Cardiovascular disease in children with chronic kidney disease. J Am Soc Nephrol 2012;23:578-585.

4 Jean G, Mayor B, Deleaval P, Lorriaux C, Hurot JM, Bresson E, Chazot C: Vascular calcification progression is an independent predic- tor of mortality in patients on haemodialysis. Nephron 2015;130:169-174.

5 Scialla JJ, Wolf M: Roles of phosphate and fibroblast growth factor 23 in cardiovascular disease. Nat Rev Nephrol 2014;10:268-278.

-6 Baia LC, Heilberg IP, Navis G, de Borst MH; NIGRAM Investigators: Phosphate and FGF23 homeostasis after kidney transplantation. Nat Rev Nephrol 2015;11:656-666. 
7 Noris M, Remuzzi G: Atypical hemolytic-uremic syndrome. N Engl J Med 2009;361:16761687.

-8 Noris M, Remuzzi G: Glomerular diseases dependent on complement activation, including atypical hemolytic uremic syndrome, membranoproliferative glomerulonephritis, and C3 glomerulopathy: core curriculum 2015. Am J Kidney Dis 2015;66:359-375.

-9 Hertle E, Stehouwer CD, van Greevenbroek MM: The complement system in human cardiometabolic disease. Mol Immunol 2014;61: 135-148.

10 Mamane Y, Chung Chan C, Lavallee G, Morin N, Xu LJ, Huang J, Gordon R, Thomas W, Lamb J, Schadt EE, Kennedy BP, Mancini JA: The C3a anaphylatoxin receptor is a key mediator of insulin resistance and functions by modulating adipose tissue macrophage infiltration and activation. Diabetes 2009;58:20062017.

11 Wlazlo N, van Greevenbroek MM, Ferreira I, Feskens EJ, van der Kallen CJ, Schalkwijk CG, Bravenboer B, Stehouwer CD: Complement factor 3 is associated with insulin resistance and with incident type 2 diabetes over a 7 -year follow-up period: the CODAM study. Diabetes Care 2014;37:1900-1909.

-12 Barbu A, Hamad OA, Lind L, Ekdahl KN, Nilsson B: The role of complement factor C3 in lipid metabolism. Mol Immunol 2015;67: 101-107.

13 van Greevenbroek MM, Jacobs M, van der Kallen CJ, Blaak EE, Jansen EH, Schalkwijk CG, Feskens EJ, Stehouwer CD: Human plasma complement $\mathrm{C} 3$ is independently associated with coronary heart disease, but only in heavy smokers (the CODAM study). Int J Cardiol 2012;154:158-162.

-14 Onat A, Hergenc G, Can G, Kaya Z, Yuksel H: Serum complement C3: a determinant of cardiometabolic risk, additive to the metabolic syndrome, in middle-aged population. Metabolism 2010;59:628-634
15 Keller TT, van Leuven SI, Meuwese MC, Wareham NJ, Luben R, Stroes ES, Hack CE, Levi M, Khaw KT, Boekholdt SM: Serum levels of mannose-binding lectin and the risk of future coronary artery disease in apparently healthy men and women. Arterioscler Thromb Vasc Biol 2006;26:2345-2350.

-16 Prugger C, Luc G, Haas B, Arveiler D, Machez E, Ferrieres J, Ruidavets JB, Bingham A, Montaye M, Amouyel P, Yarnell J, Kee F, Ducimetiere P, Empana JP; PRIME Study Group: Adipocytokines and the risk of ischemic stroke: the PRIME Study Group. Ann Neurol 2012;71:478-486.

17 Cavusoglu E, Eng C, Chopra V, Ruwende C, Yanamadala S, Clark LT, Pinsky DJ, Marmur JD: Usefulness of the serum complement component $\mathrm{C} 4$ as a predictor of stroke in $\mathrm{pa}$ tients with known or suspected coronary artery disease referred for coronary angiography. Am J Cardiol 2007;100:164-168.

18 Wu G, Hu W, Shahsafaei A, Song W, Dobarro M, Sukhova GK, Bronson RR, Shi GP, Rother RP, Halperin JA, Qin X: Complement regulator CD59 protects against atherosclerosis by restricting the formation of complement membrane attack complex. Circ Res 2009;104: 550-558.

19 Lindberg S, Pedersen SH, Mogelvang R, Galatius S, Flyvbjerg A, Jensen JS, Bjerre M: Soluble form of membrane attack complex independently predicts mortality and cardiovascular events in patients with ST-elevation myocardial infarction treated with primary percutaneous coronary intervention. Am Heart J 2012;164:786-792.

20 Speidl WS, Exner M, Amighi J, Kastl SP, Zorn G, Maurer G, Wagner O, Huber K, Minar E, Wojta J, Schillinger M: Complement component $\mathrm{C5a}$ predicts future cardiovascular events in patients with advanced atherosclerosis. Eur Heart J 2005;26:2294-2299.
21 Lines SW, Richardson VR, Thomas B, Dunn EJ, Wright MJ, Carter AM: Complement and cardiovascular disease - the missing link in haemodialysis patients? Nephron 2016, Epub ahead of print.

22 Nagaraj N, Matthews KA, Shields KJ, BarinasMitchell E, Budoff MJ, El Khoudary SR: Complement proteins and arterial calcification in middle aged women: cross-sectional effect of cardiovascular fat. The SWAN Cardiovascular Fat Ancillary Study. Atherosclerosis 2015; 243:533-539.

23 Hauser AC, Derfler K, Stockenhuber F, Janata $\mathrm{O}$, Balcke P: Generation of the membrane attack complex during haemodialysis: impact of classical and alternative pathway components. Clin Sci (Lond) 1990;79:471-476.

24 Selby NM, Lambie SH, Camici PG, Baker CS, McIntyre CW: Occurrence of regional left ventricular dysfunction in patients undergoing standard and biofeedback dialysis. Am J Kidney Dis 2006;47:830-841.

25 Assa S, Hummel YM, Voors AA, Kuipers J, Westerhuis R, Groen H, Bakker SJ, Muller Kobold AC, van Oeveren W, Struck J, de Jong PE, Franssen CF: Hemodialysis-induced regional left ventricular systolic dysfunction and inflammation: a cross-sectional study. Am J Kidney Dis 2014;64:265-273.

26 King R, Tiede C, Simmons K, Fishwick C, Tomlinson D, Ajjan R: Inhibition of complement $\mathrm{C} 3$ and fibrinogen interaction: a potential novel therapeutic target to reduce cardiovascular disease in diabetes. Lancet 2015; 385(suppl 1):S57.

27 Daina E, Noris M, Remuzzi G: Eculizumab in a patient with dense-deposit disease. $\mathrm{N}$ Engl J Med 2012;366:1161-1163.

28 Cofiell R, Kukreja A, Bedard K, Yan Y, Mickle AP, Ogawa M, Bedrosian CL, Faas SJ: Eculizumab reduces complement activation, inflammation, endothelial damage, thrombosis, and renal injury markers in aHUS. Blood $2015 ; 125: 3253-3262$ 